\title{
Sealants in Dentistry: Outcomes of the ORCA Saturday Afternoon Symposium 2007
}

\author{
C.H. Splieth ${ }^{a} \quad$ K.R. Ekstrand ${ }^{c} \quad$ M. Alkilzy ${ }^{a} \quad$ J. Clarkson ${ }^{d} \quad H$. Meyer-Lueckel $^{b}$ \\ S. Martignon $^{f} \quad$ S. Paris ${ }^{b} \quad$ N.B. Pitts ${ }^{d} \quad$ D.N. Ricketts ${ }^{e} \quad$ C. van Loveren ${ }^{g}$ \\ a Department of Preventive and Pediatric Dentistry, Ernst Moritz Arndt University, Greifswald, and \\ ${ }^{b}$ Clinic for Conservative Dentistry and Periodontology, Christian Albrechts University Kiel, Kiel, Germany; \\ 'Department of Cariology and Endodontics, University of Copenhagen, Copenhagen, Denmark; \\ dDental Health Services Research Unit and e Department of Restorative Dental Care and Clinical Dental Sciences, \\ University of Dundee, Dundee, UK; ${ }^{\dagger}$ Caries Research Unit UNICA, Universidad El Bosque, Bogota, Colombia; \\ ${ }^{9}$ Cariologie Endodontologie Pedodontologie, Academisch Centrum voor Tandheelkunde Amsterdam, Amsterdam, \\ The Netherlands
}

\section{Key Words}

Caries $\cdot$ Children $\cdot$ Infiltration $\cdot$ Proximal sealing $\cdot$ Sealants

\begin{abstract}
Sealants are a successful tool in caries prevention, but their role in preventive strategies after the caries decline has to be discussed. A survey of paediatric departments across Europe revealed that indications for pit and fissure sealants vary considerably, both nationally and internationally. Evidence for effectiveness of sealants in controlling caries in posterior teeth implies that sealants should be an integrated part of management of pit and fissure caries. Still, the indication for occlusal sealants seems to be shifting from primary prevention to a therapeutic decision for caries management of lesions in enamel and the outer part of the dentine. Sealants are also an interesting concept for caries management in approximal surfaces. Clinical trials suggest that novel techniques of sealing or infiltrating approximal lesions show promise. However, approximal sealing techniques are as complex to apply and time-consuming as approximal fillings. The article proposes guidelines for teaching on the use of sealants.

Copyright ๑ 2009 S. Karger AG, Basel
\end{abstract}

The ORCA Saturday Afternoon Symposium 2007 in Elsinore, Denmark, had the title 'To Seal or Not to Seal'. The overall aim of this article, based on the presentations at the symposium, is to present and discuss contemporary views and evidence of sealants related to primary and secondary caries prevention. In keeping with the aims of ORCA, a further aim is to identify teaching policies concerning sealants and to help in development of guidelines for future teaching.

In the first section of this article, the current caries situation in children and adolescents is highlighted with special attention to the caries decline and its consequences for future preventive strategies. Then, the results of a questionnaire on the use of sealants in Europe are presented and perspectives for the indication of occlusal sealants are developed with special emphasis on erupting teeth. Finally, the newly evolving field of approximal sealing and infiltration is reviewed.

\section{Current Caries Status}

There is no doubt that caries experience, measured by the def/DMF index, among children and adolescents has decreased in many countries over the last 30 years [Mar-

Prof. Dr. Christian H. Splieth

Präventive Zahnmedizin und Kinderzahnheilkunde

Rotgerberstrasse 8

DE-17487 Greifswald (Germany)

Tel. +49 3834867 101, Fax +49 3834867 299, E-Mail splieth@uni-greifswald.de 
Table 1. Number of dental schools that claim to apply sealants routinely or on indication, to apply sealants in the deciduous dentition and to apply sealants to approximal surfaces in the 13 European countries

\begin{tabular}{|c|c|c|c|c|c|c|c|c|c|c|c|c|c|c|}
\hline & $\mathrm{DE}$ & FR & UK & NL & $\mathrm{CZ}$ & $\mathrm{BE}$ & $\mathrm{CH}$ & FI & SE & $\mathrm{DK}$ & IS & $\mathrm{IE}$ & IL & All \\
\hline \multicolumn{15}{|c|}{ On what basis do you seal in your department? ${ }^{1}$} \\
\hline Routinely & 2 & 0 & 0 & 0 & 0 & 0 & 0 & 0 & 0 & 0 & 1 & 0 & 0 & 3 \\
\hline On indication & 15 & 6 & 5 & 3 & 3 & 2 & 2 & 2 & 2 & 2 & 0 & 1 & 1 & 44 \\
\hline \multicolumn{15}{|c|}{ Do you seal the deciduous dentition in your department? } \\
\hline Yes & 11 & 4 & 4 & 1 & 2 & 0 & 1 & 0 & 1 & 1 & 1 & 0 & 1 & 27 \\
\hline No & 6 & 2 & 1 & 2 & 1 & 2 & 1 & 2 & 1 & 1 & 0 & 1 & 0 & 20 \\
\hline \multicolumn{15}{|c|}{ Do you seal approximal surfaces in your department? } \\
\hline Yes & 1 & 1 & 0 & 0 & 0 & 0 & 1 & 0 & 0 & 2 & 0 & 0 & 0 & 5 \\
\hline No & 16 & 5 & 5 & 3 & 3 & 2 & 1 & 2 & 2 & 0 & 1 & 1 & 1 & 42 \\
\hline
\end{tabular}

${ }^{1}$ Those departments that indicated to place sealants routinely did so within 1 year after eruption.

thaler et al., 1996; WHO, 2003]. The reason for this drop is not fully understood, but increased access to fluoride has been a major player in the change [Bratthall et al., 1996]. In a few countries, e.g. Lithuania, China and Morocco, the DMFT has increased during the last 20 years [WHO, 2003].

McDonald and Sheiham [1992] stated that when caries prevalence falls, caries in the most susceptible sites (occlusal) decreases by the smallest proportion, while the least susceptible sites (smooth and approximal surfaces) exhibit the greatest reduction. This statement is supported by data from Sweden [Mejàre et al., 1998] and Denmark [Ekstrand et al., 2007a].

The following can be stated concerning caries experience in children and adolescents below the age of 18 :

- In the primary dentition, caries incidence is highest on occlusal and approximal surfaces of molars.

- In the permanent dentition of children and adolescents, occlusal surfaces of molars are the most frequently affected sites, while occlusal surfaces of premolars are less affected.

- The relatively long eruption periods of permanent first and second molars should be regarded as risk periods for occlusal caries development [Carvalho et al., 1989, 1991; Ekstrand and Christiansen, 2005].

Thus, the caries problem in children and adolescents is still largely at occlusal surfaces, where plaque stagnation is promoted because the morphology prevents selfcleaning by food, tongue, cheeks and lips, and makes cleaning by oral hygiene measures difficult. The same conditions prevail at approximal surfaces. In such sites, sealants can serve as a mechanical barrier against accumulation and maturation of plaque. Thus, their current (recommended) use in Europe and future perspectives on sealants is a key issue.

\section{Use of Sealants in Europe}

A questionnaire consisting of 21 closed questions (questionnaire can be obtained from C. van Loveren) was sent to 111 paediatric departments identified in 13 European countries in the beginning of 2007 (42\% response: 17 departments from Germany, 6 France, 5 United Kingdom, 3 The Netherlands, 3 Czech Republic, 2 Belgium, 2 Switzerland, 2 Finland, 2 Sweden, 2 Denmark, 1 Iceland, 1 Ireland and 1 Israel). Half of the countries (Finland, France, Germany, Ireland, Israel, Sweden and United Kingdom) were reported to have national guidelines, while the others (Belgium, Czech Republic, Denmark, Iceland, The Netherlands and Switzerland) were not.

Only a few departments (6\%) used pit and fissure sealants routinely within a year after complete eruption; the others used sealants only on specific indication (table 1). Primary teeth were occasionally sealed in $57 \%$ of the departments, but not in Belgium, Finland or Ireland. Only a few departments, in Denmark, Switzerland, France and Germany (1 out of 17), sealed approximal surfaces. Although the decision to seal was said to be based on caries risk, caries risk seemed particularly to be taken into account for the decision to seal caries-free fissures (table 2). As an indicator for caries risk the presence of active caries 
Table 2. Number of dental schools claiming to place sealants in fissures with the described appearance in children

\begin{tabular}{|c|c|c|c|c|c|c|c|c|c|c|c|c|c|c|}
\hline & $\mathrm{DE}$ & FR & UK & NL & $\mathrm{CZ}$ & $\mathrm{BE}$ & $\mathrm{CH}$ & FI & SE & DK & IS & IE & IL & All \\
\hline Total number of schools & 17 & 6 & 5 & 3 & 3 & 2 & 2 & 2 & 2 & 2 & 1 & 1 & 1 & 47 \\
\hline \multicolumn{15}{|c|}{ Normal enamel translucency } \\
\hline Low-risk child & 3 & 0 & 0 & 0 & 0 & 0 & 1 & 0 & 0 & 0 & 0 & 0 & 0 & 4 \\
\hline Medium-risk child & 9 & 6 & 3 & 1 & 1 & 2 & 1 & 0 & 0 & 0 & 1 & 1 & 1 & 26 \\
\hline High-risk child & 16 & 6 & 5 & 1 & 2 & 2 & 2 & 2 & 2 & 1 & 1 & 1 & 1 & 42 \\
\hline
\end{tabular}

Shiny appearance of the surface of the opaque area with different degrees of whitish or brownish discoloration

\begin{tabular}{|c|c|c|c|c|c|c|c|c|c|c|c|c|c|}
\hline Low-risk child & 8 & 5 & 4 & 0 & 1 & 1 & 1 & 0 & 0 & 1 & 0 & 1 & 1 \\
\hline Medium-risk child & 12 & 5 & 4 & 0 & 3 & 1 & 1 & 1 & 0 & 1 & 1 & 1 & 1 \\
\hline High-risk child & 13 & 5 & 3 & 1 & 2 & 2 & 1 & 2 & 2 & 2 & 1 & 1 & 1 \\
\hline
\end{tabular}

Opaque enamel with a dull-whitish surface without cavitation

\begin{tabular}{lllllllllllllll} 
Low-risk child & 8 & 5 & 4 & 2 & 0 & 1 & 2 & 0 & 0 & 1 & 0 & 1 & 1 & 25 \\
Medium-risk child & 11 & 5 & 4 & 3 & 3 & 2 & 2 & 1 & 0 & 1 & 1 & 1 & 1 & 36 \\
High-risk child & 12 & 5 & 5 & 3 & 2 & 2 & 1 & 2 & 2 & 2 & 1 & 1 & 1 & 39 \\
\hline
\end{tabular}

Dull-whitish enamel with localized surface destruction in enamel, but not reaching the dentin (cavitation in enamel)

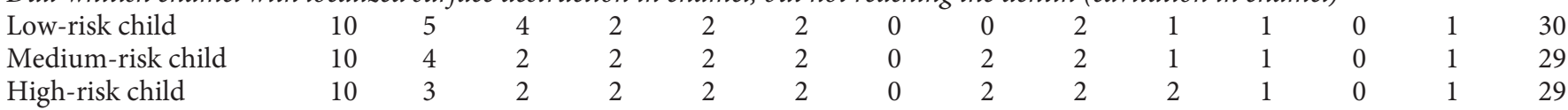

\begin{tabular}{|c|c|c|c|c|c|c|c|c|c|c|c|c|c|c|}
\hline \multicolumn{15}{|c|}{ Initial dentin caries without cavitation } \\
\hline Low-risk child & 4 & 2 & 2 & 2 & 0 & 1 & 0 & 1 & 1 & 1 & 1 & 0 & 0 & 15 \\
\hline Medium-risk child & 5 & 1 & 0 & 1 & 0 & 1 & 0 & 0 & 1 & 1 & 1 & 0 & 0 & 11 \\
\hline High-risk child & 5 & 0 & 0 & 1 & 0 & 1 & 0 & 0 & 1 & 1 & 1 & 0 & 0 & 10 \\
\hline
\end{tabular}

\begin{tabular}{lcccccccccccccc}
\hline Initial dentin caries with cavitation & & & & & & & & & & \\
At all risk levels & 4 & 0 & 0 & 1 & 0 & 0 & 0 & 0 & 0 & 1 & 0 & 0 & 0
\end{tabular}

\begin{tabular}{lllllllllllll}
\hline $\begin{array}{l}\text { Deep dentin caries } \\
\text { At all risk levels }\end{array}$ & 3 & 0 & 0 & 0 & 0 & 0 & 0 & 0 & 0 & 0 & 0 & 0 \\
\hline
\end{tabular}

Active caries with cavitation on filled surface

$\begin{array}{llllllllllllllll}\text { At all risk levels } & 2 & 0 & 0 & 0 & 0 & 0 & 0 & 0 & 0 & 0 & 0 & 0 & 0 & 2\end{array}$

Do you seal when the X-ray shows occlusal enamel radiolucencies just beyond the enamel dentinal junction?

$\begin{array}{llllllllllllllll}\text { Yes } & 0 & 3 & 1 & 2 & 0 & 1 & 0 & 0 & 0 & 2 & 0 & 0 & 0 & 9\end{array}$

was used most frequently, followed by fissure morphology and caries status of the respective fissures (table 3). Departments were very reluctant to seal when the caries lesion involved dentine. Only 10-15 departments would place sealants in fissures with a clinical appearance indicative of initial dentin caries without cavitation; $70 \%$ of the departments would place a filling (tables 2,4$)$. When caries had passed the enamel-dentine junction according to a radiograph, the same percentage of departments preferred to place a filling rather than sealants (table 4). Only $10 \%$ of the departments, however, claimed to take radiographs especially for this purpose. Restorers of early lesions (dull-whitish enamel with localized surface de- struction in enamel, but not reaching the dentine: cavitation in enamel) were found in the UK, Switzerland, France and Germany, while sealers of later lesions (initial dentin caries with cavitation) were found in Denmark, the Netherlands and Germany (tables 2, 4). Figures 1 and 2 show the variation in departments across Europe to seal or restore fissures related to the caries status and the estimated caries risk.

In conclusion, the indication when to use pit and fissure sealants varies considerably among the departments of paediatric dentistry both nationally and internationally across Europe. 
Table 3. Average rating of various risk indicators according to their frequency of use $(1=$ most frequent, $13=$ least frequent $)$ by 47 dental schools in various European countries

Does caries risk influence your decision to apply sealants? If so, please rank (1-13) the following items according to the frequency they are used in your department to assess caries risk when applying sealants

\begin{tabular}{|c|c|c|c|c|c|c|}
\hline $\begin{array}{l}\text { Presence of active } \\
\text { caries lesions } \\
2.8 \pm 1.6\end{array}$ & $\begin{array}{l}\text { Morphology } \\
\text { of the fissures } \\
3.2 \pm 1.3\end{array}$ & $\begin{array}{l}\text { Caries status } \\
\text { of the fissure } \\
4.0 \pm 2\end{array}$ & $\begin{array}{l}\operatorname{dmf} \\
4.2 \pm 1.9\end{array}$ & $\begin{array}{l}\text { DMF } \\
5.5 \pm 3.3\end{array}$ & $\begin{array}{l}\text { Amount of } \\
\text { dental plaque } \\
5.5 \pm 1.9\end{array}$ & $\begin{array}{l}\text { Dentist's experi- } \\
\text { ence and feeling } \\
7.0 \pm 2.7\end{array}$ \\
\hline Diet & $\begin{array}{l}\text { Use of fluoride } \\
\text { toothpaste }\end{array}$ & $\begin{array}{l}\text { Socioeconomic } \\
\text { background }\end{array}$ & $\begin{array}{l}\text { Amount of mutans } \\
\text { streptococci }\end{array}$ & Salivary flow & $\begin{array}{l}\text { Amount of } \\
\text { lactobacilli }\end{array}$ & \\
\hline $7.3 \pm 2.7$ & $7.8 \pm 2.1$ & $7.8 \pm 2.7$ & $9.6 \pm 1.9$ & $9.9 \pm 1.8$ & $10.3 \pm 1.5$ & \\
\hline
\end{tabular}

Table 4. Number of dental schools claiming to place fillings in fissures with the described appearance

\begin{tabular}{|c|c|c|c|c|c|c|c|c|c|c|c|c|c|c|}
\hline & $\mathrm{DE}$ & FR & UK & NL & $\mathrm{CZ}$ & $\mathrm{BE}$ & $\mathrm{CH}$ & FI & SE & $\mathrm{DK}$ & IS & IE & IL & All \\
\hline Total number of schools & 17 & 6 & 5 & 3 & 3 & 2 & 2 & 2 & 2 & 2 & 1 & 1 & 1 & 47 \\
\hline \multicolumn{15}{|c|}{ Normal enamel translucency } \\
\hline & 1 & 0 & 0 & 0 & 0 & 0 & 0 & 0 & 0 & 0 & 0 & 0 & 0 & 1 \\
\hline \multicolumn{15}{|c|}{ Shiny appearance of the surface of the opaque area with different degrees of whitish or brownish discoloration } \\
\hline & 2 & 1 & 0 & 0 & 0 & 0 & 0 & 0 & 0 & 0 & 0 & 0 & 0 & 3 \\
\hline \multicolumn{15}{|c|}{ Opaque enamel with a dull-whitish surface without cavitation } \\
\hline & 2 & 1 & 0 & 0 & 0 & 0 & 1 & 0 & 0 & 0 & 0 & 0 & 0 & 4 \\
\hline \multicolumn{15}{|c|}{ Dull-whitish enamel with localized surface destruction in enamel, but not reaching the dentin (cavitation in enamel) } \\
\hline & 7 & 2 & 2 & 0 & 0 & 0 & $2^{\circ}$ & 0 & 0 & 0 & 0 & 0 & 0 & 13 \\
\hline \multicolumn{15}{|c|}{ Initial dentin caries without cavitation } \\
\hline & 14 & 4 & 5 & 2 & 2 & 1 & 2 & 1 & 0 & 0 & 0 & 1 & 1 & 33 \\
\hline \multicolumn{15}{|c|}{ Initial dentin caries with cavitation } \\
\hline & 15 & 6 & 5 & 2 & 3 & 2 & 2 & 2 & 2 & 1 & 1 & 1 & 1 & 43 \\
\hline \multicolumn{15}{|l|}{ Deep dentin caries } \\
\hline & 15 & 6 & 5 & 3 & 3 & 2 & 2 & 2 & 2 & 2 & 1 & 1 & 1 & 45 \\
\hline \multicolumn{15}{|c|}{ Active caries with cavitation on filled surface } \\
\hline & 16 & 6 & 5 & 3 & 3 & 2 & 2 & 2 & 2 & 2 & 1 & 1 & 1 & 46 \\
\hline \multicolumn{15}{|c|}{ When you see on the X-ray occlusal enamel radiolucencies just beyond the enamel dentinal junction } \\
\hline & 13 & 3 & 5 & 1 & 2 & 0 & 2 & 2 & 2 & 0 & 1 & 1 & 1 & 33 \\
\hline
\end{tabular}

\section{Occlusal Sealants}

\section{Effectiveness}

Recent systematic reviews [Ahovuo-Saloranta et al., 2008; Mejàre et al., 2003] provide evidence for the effectiveness of sealants in controlling caries (table 5).

The data demonstrate the effectiveness of resin-based sealants over no treatment for caries prevention when applied on sound occlusal surfaces of permanent molars.
The Cochrane Review [Ahovuo-Saloranta et al., 2008] estimated that the caries-preventive effect ranges from $87 \%$ at 12 months to $60 \%$ at $48-54$ months, but heavily depends on sufficient retention of the sealant. Mejàre et al. [2003] estimated a pooled effect of 33\% for all included resin studies most of which had only a single application of resin. In these reviews, modifying effects on sealant effectiveness have been explored. Further research in both high and low caries risk children is especially need- 


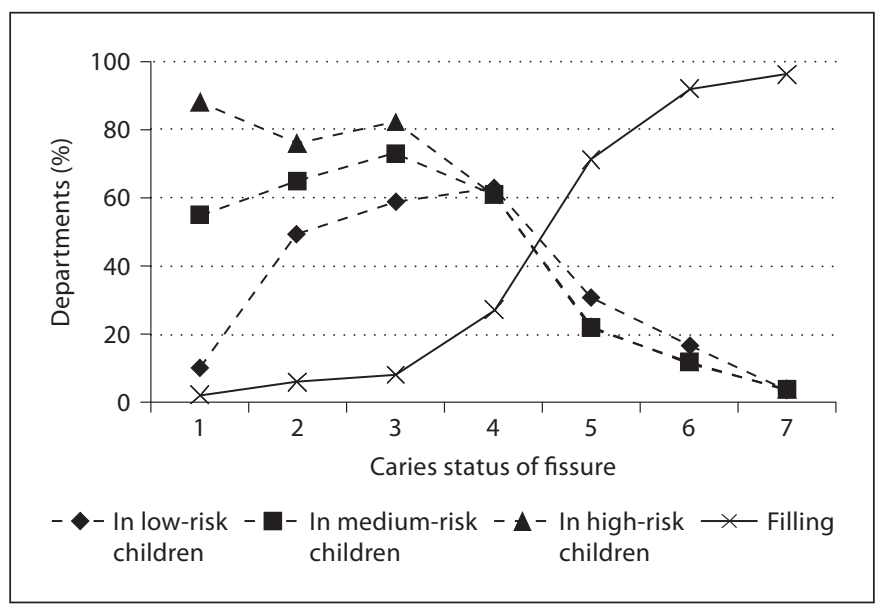

Fig. 1. Indications for sealing (dashed lines) or filling (solid line) fissures in European paediatric dentistry departments, according to caries risk of the child and caries status of the fissure: $1=$ normal enamel translucency; 2 = opaque area with different degrees of whitish or brownish discoloration and a shiny surface; $3=$ opaque enamel with a dull-whitish surface without cavitation; $4=$ dull-whitish enamel with localized surface destruction in enamel, but not reaching the dentin (cavitation in enamel); $5=$ initial dentin caries without cavitation; 6 = initial dentin caries with cavitation; 7 = deep dentin caries.

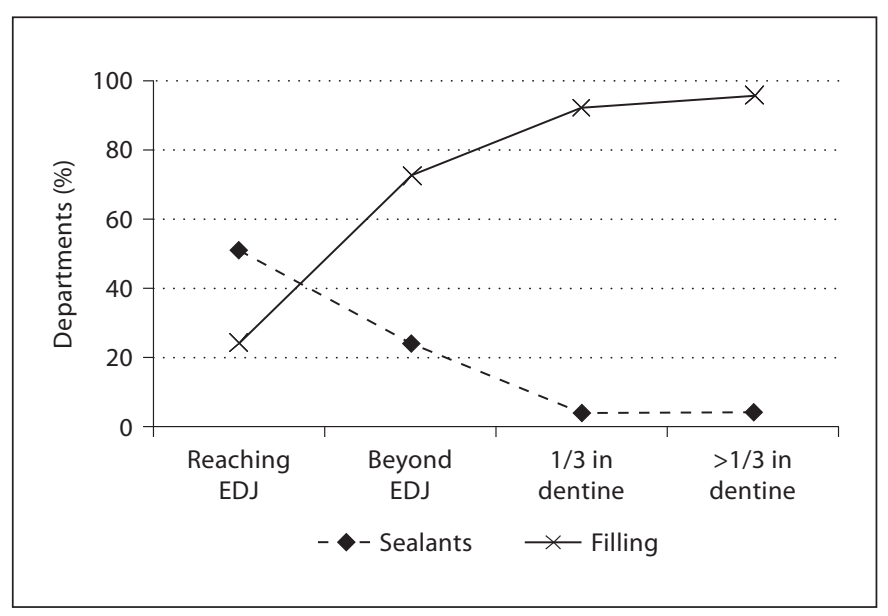

Fig. 2. Indications for sealing or filling fissures in European paediatric dentistry departments according to caries status on X-ray (from enamel-dentine junction, EDJ, into dentine).

ed. Evidence for the effectiveness of fissure sealants in the primary dentition is limited and weak.

Hiiri et al. [2006] examined the effectiveness of pit and fissure sealants versus fluoride varnishes (table 5). Few studies were included and, whilst there was some evi- dence of the superiority of pit and fissure sealants over fluoride varnish, the extent could not be determined and more research is needed before recommendations for clinical practice can be made.

Ahovuo-Saloranta et al. [2008] also compared resinbased with glass-ionomer sealants for up to 84 months with very diverging results. Three out of eight studies included found better caries-preventive effect for resinbased sealants and 2 for glass-ionomer. The remaining three studies showed no significant difference. Because of heterogeneity of the data, meta-analysis was not feasible. Beiruti al. [2006], who included 19 studies, also reached the conclusion that there was no consistent difference with respect to caries-preventive effect between the two types of sealant.

\section{Indications for Sealants in Erupting Teeth}

Until erupting teeth reach full occlusion, the fissure relief on occlusal surfaces, especially in molars, forms an almost perfect niche for plaque stagnation. Epidemiologic studies show considerable caries development on these surfaces [Marthaler et al., 1996], suggesting that preventive measures are not implemented at a sufficient level.

Tooth brushing with fluoridated toothpaste is the first choice to control caries development and the effectiveness is clearly proven [Marinho et al., 2003]. There seems to be a dose-response effect between fluoride concentration in toothpaste and the caries-preventive effect [Marinho et al., 2003]. In addition, applications of topical fluorides with higher fluoride concentrations ( $>10,000 \mathrm{ppm})$ 2-4 times per year significantly reduce caries development [Marinho et al., 2002; Mejàre et al., 2003]. Thus, tooth brushing twice a day with a $1,450-1,500$ ppm fluoridated toothpaste by trained parents and/or children, supplemented with 2-4 topical fluoride applications annually are advisable in order to control occlusal caries development during the eruption period.

Resin-based sealants require good moisture control, which is difficult to obtain in erupting teeth. Therefore, conventional sealants cannot be applied during the phase of the highest caries risk and intermediate steps are needed for this critical period of time [Araujo, 2002; Carvalho et al., 1992]. Besides non-operative measures, glass ionomer sealants might be suitable because they are less sensitive to moisture [Ahovuo-Saloranta et al., 2008; Beiruti et al., 2006]. In addition, the fluoride release from glass ionomer might be beneficial [Salar et al., 2007]. The retention rate of glass ionomer sealants is inferior to resinbased materials, but the caries-preventive effect does not seem to differ significantly from that of resin-based seal- 
Table 5. Effectiveness of sealants in systematic reviews

\begin{tabular}{|c|c|c|c|c|c|}
\hline Authors & Age groups & Selection criteria & $\begin{array}{l}\text { Duration } \\
\text { of trials }\end{array}$ & Studies & Pooled relative risk (RR) \\
\hline \multicolumn{6}{|c|}{ Pit and fissure sealants ${ }^{1}$ versus no treatment } \\
\hline \multirow{4}{*}{$\begin{array}{l}\text { Ahovuo-Saloranta } \\
\text { et al. [2008] }\end{array}$} & \multirow{4}{*}{$\begin{array}{l}\text { children and } \\
\text { adolescents }\end{array}$} & \multirow{4}{*}{$\begin{array}{l}\text { randomized or quasi-randomized } \\
\text { controlled trials }\end{array}$} & \multirow[t]{4}{*}{$\geq 1$ year } & 3 & $0.13(0.09-0.20), 12$ months \\
\hline & & & & 3 & $0.22(0.15-0.34), 24$ months \\
\hline & & & & 3 & $0.30(0.22-0.40), 36$ months \\
\hline & & & & 3 & 0.40 (0.31-0.51), 48-54 months \\
\hline Mejàre et al. [2003] & $\begin{array}{l}\text { up to } 14 \text { years } \\
\text { at start }\end{array}$ & $\begin{array}{l}\text { randomized or quasi-randomized } \\
\text { controlled trials or controlled clinical trials }\end{array}$ & $>2$ years & 13 & 0.67 \\
\hline \multicolumn{6}{|c|}{ Pit-and-fissure sealants versus fluoride varnish } \\
\hline Hiiri et al. [2006] & below age 20 & random or quasi-random allocation study & $\geq 1$ year & 4 & $\begin{array}{l}0.25(0.01-4.95), 12 \text { months } \\
0.74(0.58-0.95), 23 \text { months } \\
0.36(0.21-0.61), 24 \text { months } \\
0.48(0.29-0.79), 9 \text { years } \\
1 \text { study NS }\end{array}$ \\
\hline
\end{tabular}

${ }^{1}$ Two studies using glass ionomer cements, the rest second- or third-generation resin-based sealants.

ants (see above). When moisture cannot be controlled, as in erupting teeth or in uncooperative patients, glass ionomer is often the only material which can be used as a sealant.

\section{Sealing Caries Lesions}

Sealing of caries lesions is a controversially discussed topic. Four types of study have been looking into sealing deep caries lesions with or without bevelling the entrance of the lesion [Mertz-Fairhurst et al., 1998; Ricketts et al., 2006], as stepwise excavation or by covering the lesion with a crown such as in the Hall technique [Innes et al., 2007]. In deep lesions (extending into the pulpal half of dentine) complete caries removal carries a risk of pulpal exposure (approximately $40 \%$ in permanent teeth and $53 \%$ in primary teeth) [Ricketts et al., 2006]. There is growing evidence that simply 'sealing' deep lesions, by placing restorative materials without first removing all carious dentine, is effective in stopping the caries process.

In radiographically visible lesions which, according to Ricketts et al. [2006], would extend well into dentine and would probably be heavily infected with no tooth preparation, acid etching alone was shown to reduce bacterial load by up to $75 \%$. After sealing with restorative materials there was a continued reduction in the number of viable organisms within the lesion. At the 1-year recall there was almost a 100\% reduction [Jensen and Handelman, 1980]. In another study, an experimental group of radiographi- cally visible occlusal lesions underwent ultraconservative caries removal (a composite restoration being placed after simply bevelling the enamel at the entrance to the fissure to ensure a good bond to sound enamel) while the control group underwent complete caries removal and restoration with amalgam. For up to 10 years, no problems were reported with loss or deterioration of restorations, or signs or symptoms of pulp pathology in either group [Mertz-Fairhurst et al., 1998]. Finally, an evaluation of the Hall technique [Innes et al., 2007], in which preformed stainless steel crowns are placed over carious primary molars without any caries removal, gives further evidence that sealing in mature caries lesions leads to arrest of the caries process by depriving organisms within the lesion of the intra-oral substrate they need to survive.

These studies, and recent reviews which seriously consider sealants in managing caries lesions [Griffin et al., 2008; Oong et al., 2008], question the conventional wisdom that all dentine caries needs to be removed and will open a new field of research into using sealants for dentinal caries lesions.

\section{Sealant Indication in Low Caries Prevalence Populations}

As it takes time for the occlusal surface to emerge into the oral cavity and to erupt to a stage where it can be sealed, it is likely that initial stages of caries have developed during that period [Carvalho et al., 1989]. Thus, the 
many studies in which it is claimed that sound surfaces were sealed [e.g. Ahovuo-Saloranta, 2008], may have sealed surfaces with initial stages of caries. Sealing with resins can be considered as a kind of late treatment compared to tooth brushing and fluoride treatment [Carvalho et al., 1991]. In fact, as the occlusal surfaces of erupting teeth often show the initial stages of caries, it is more correct to see sealants as a therapeutic treatment than as a purely preventive treatment. On the basis of the above, and in the light of the low caries progression rate seen in many countries, the therapeutic indications for fissure sealants would logically include active caries lesions. Nevertheless, an assessment of the individual patient and tooth seems to be the best basis for deciding whether sealants are indicated.

From the above, the question could be raised, of whether sealants are necessary in daily practice, when children follow comprehensive, free-of-charge community dental programmes. In Nexö, Denmark, a non-operative caries treatment programme (NOCTP) has been evaluated since 1987 [Ekstrand and Christiansen, 2005]. The programme is based on: (1) education of parents, children and adolescents in understanding dental caries as a localized disease; (2) intensive training in home-based plaque control, and (3) early professional, non-operative intervention, including professional plaque removal, local application of $2 \% \mathrm{NaF}$ and application of sealants. Emphasis is placed on plaque removal at home, using a special technique of brushing perpendicular to the erupting molars. Fissure sealants were used in the NOCTP only according to a strict indication: in cases of continued occlusal caries progression despite fluoride application and plaque control.

Representative Danish data on 15-year-olds [Ekstrand et al., 2007a] showed a mean DMF-S of 2.97 and a mean number of 3.06 sealants, mostly on permanent molars (34\%). The correlations between mean number of sealed teeth and mean DMFS at either municipality or individual level were low. In three groups of children from Nexö, born in 1981, 1982 and 1989, and who followed the NOCTP, the mean DMF-S of $<1$ in 15-year-olds was well below the level of $>2.9$ DMF-S in the corresponding national cohorts [www.nexodent.com], while the mean number of sealants decreased continuously (fig. 3). The very low DMF-S in Nexö, and therefore the success of non-operative treatment, often as an alternative to sealants, was also supported by low rate of dentinal occlusal caries diagnosed on the bitewing radiographs [Ekstrand and Christiansen, 2008].

Sealants in Dentistry

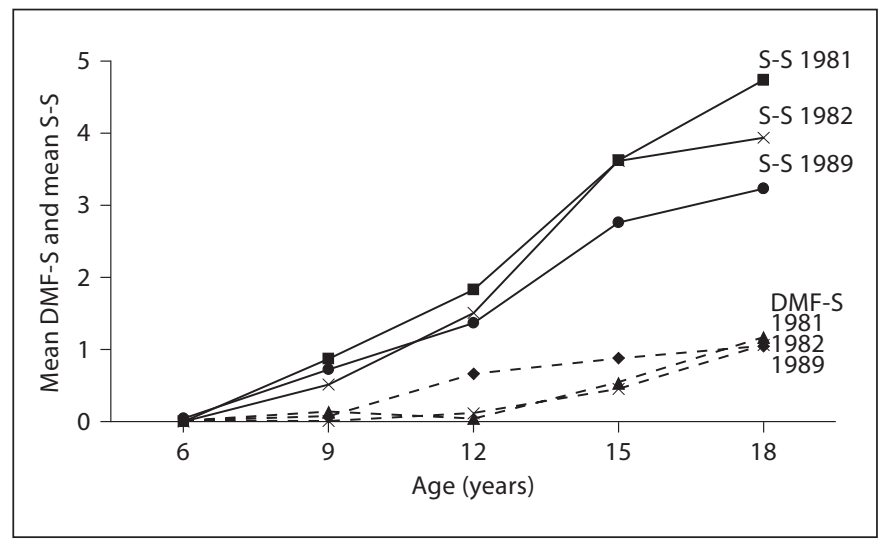

Fig. 3. Caries development (mean DMF-S) and number of sealants (mean S-S) in three cohorts of children who followed a nonoperative caries treatment programme from age 5 to 18 (groups 1981 and 1982) and from the age 1 to 18 (group 1989).

Thus, the use of sealants does not automatically guarantee low caries prevalence [Ekstrand et al., 2007a]. In contrast, low DMF-S values can be achieved with strict indications for sealants under the conditions that children follow a thorough preventive regime [Ekstrand and Christiansen, 2005, 2008]. The latter statement is supported in a risk-specific analysis from Germany performed by Heyduck et al. [2006], who could show that sealants often failed if caries activity was not controlled with non-operative measures.

In conclusion, fissure sealants have a place in daily practice, even under the most comprehensive community dental programmes and under ideal conditions such as free care and unlimited access to dental care for the child population. Sealants should be integrated into a non-operative treatment approach to control occlusal caries development in daily practice. Otherwise sealants often fail in the long run.

\section{Approximal Sealing}

\section{Approximal Sealing with Resin}

Longitudinal data from Sweden and Denmark have shown that despite organized child dental health services many approximal lesions in young adults progress, albeit very slowly [Mejàre et al., 1998, 1999, 2004; Martignon et al., 2009]. The concept of arresting caries by applying a resin barrier to the surface, as in occlusal fissure sealing, has also been transferred to approximal surfaces.

Caries Res 2010;44:3-13 
Penetration of adhesive into artificial lesions was already described in the 1970s [Davila et al., 1975; Robinson et al., 1976] and extended to sealants by Tanaka [2000].

The general suitability of dental adhesives or fissure sealants for sealing artificial initial enamel caries was demonstrated in vitro [Donly and Ruiz, 1992; Garçía-Godoy et al., 1997; Goepferd and Olberding, 1989; Gray and Shellis, 2002; Robinson et al., 2001; Rodda, 1983; Schmidlin et al., 2004]. While there was almost complete penetration of rather shallow artificial lesions, in most studies a material layer seemed to be left on the tooth surface. Thus, the observed arrest of lesion progression must be attributed to surface sealing as well as to penetration of resin into the caries lesion [Donly and Ruiz, 1992; GarçíaGodoy et al., 1997; Goepferd and Olberding, 1989]. Recent studies using artificial lesions showed that if the lesion body is sufficiently penetrated with resin, the covering resin coat on the lesion surface is not a requirement to prevent caries progression [Mueller et al., 2006; Paris et al., 2006]. With some commercially available adhesives and fissure sealants a nearly complete penetration of the lesion body could be achieved [Gray and Shellis, 2002; Meyer-Lueckel et al., 2005; Rodda, 1983]. These fairly encouraging results from artificial lesions could, however, not be confirmed for natural lesions [Davila et al., 1975; Paris et al., 2007b]. The small penetration depths of commercially available adhesives into natural lesions were attributed to the relatively low pore volume of the surface layer and to the inappropriate physical properties of the available adhesives for penetration [Paris et al., 2007b].

In a clinical study on Danish and Colombian young adults [Martignon et al., 2006], space for approximal sealing was created by placing an orthodontic band between the teeth for 2 days. At a second appointment, the band was removed and proximal sealing conducted with an adhesive material. The split mouth study included approximal lesions with radiolucencies in enamel or in the outer third of the dentine. After 18 months, sealing of the lesions was more effective for preventing lesion progression than flossing as $22 \%$ of the test lesions had progressed compared to $47 \%$ of the control lesions $(\mathrm{p}<0.05)$. The same trend was seen after $3-4$ years as $22 \%$ of the test lesions had progressed compared to $68 \%$ of the control lesions ( $\mathrm{n}=37$ ) [Martignon et al., 2009]. Another study on proximal sealing was unable to show any difference compared with fluoride application due to low caries incidence in the study group [Gomez et al., 2005].

While sealing with resin seems to be a promising novel method for controlling progression of approximal lesions, several matters have to be considered, such as the caries prevalence and progression rate in the population. Because enamel lesions progress into dentine more quickly in primary teeth than in permanent teeth [Schwartz et al., 1984], it could be wise for primary teeth to seal lesions that are radiographically not yet extending into dentine. More accurate methods for detecting and monitoring early enamel demineralization would be helpful and several approaches are currently under investigation [Ekstrand et al., 2007b; Ismail et al., 2007; Ricketts et al., 2007]. Using rubber dam will diminish the possibility of contamination of the dental material [Tagami et al., 1988]. An etching time of $1 \mathrm{~min}$ is preferred because of the variability of approximal lesions. Furthermore, it could be beneficial to dry etched surfaces with ethanol [Gray and Shellis, 2002].

\section{Approximal Sealing with Polyurethane Tape}

Since application of fluid material in approximal areas may be hard to control, a pre-cured adhesive patch could provide a continuous, uniform, impermeable coating, with the further possible benefit of avoiding the oxygen inhibition layer. Schmidlin et al. [2005, 2006a, b] demonstrated that in vitro such a patch showed complete protection for the underlying enamel from demineralization and provided excellent protection against the formation of caries-like lesions in a bacterial model.

In a 2-year study [Alkilzy et al., 2009], patch-sealed initial approximal lesions were compared with lesions treated by flossing at home and by fluoride application. The sealants showed good retention, marginal adaptation and colour. In both groups, most lesions were stable and there were no significant differences in the numbers regressing or progressing. No changes in the medical history could be detected and no local or systemic effects, such as allergic or toxic reactions, were observed. Teeth remained vital and no relevant differences in plaque accumulation or gingival status were found between sealed and control teeth. This study demonstrates the lack of adverse reactions to sealing initial approximal lesions with polyurethane tape but no clear benefit could be detected over a non-operative approach with flossing and fluoride application. This could be due to the low caries incidence in the examined population, consisting mostly of young adults with high socioeconomic status who had to comply with the study for 2 years.

\section{Infiltration of Caries Lesions}

In contrast to caries sealing, where the protective resin layer is established on the tooth surface, the aim of caries infiltration is to occlude lesion pores with low-viscos- 
ity resins in order to create a diffusion barrier and hence arrest caries progression. If the lesion body of artificial caries is sufficiently well infiltrated with resin, lesion progression is significantly reduced in a cariogenic environment in vitro [Meyer-Lueckel and Paris, 2008b; Paris et al., 2006]. Moreover, infiltration might stabilize the fragile lesion structure. In contrast to application of a sealant or a patch, for infiltration teeth only need to be separated by wedges in a one-visit procedure.

Resin penetration into artificial caries lesions can be enhanced when the lesion surface is etched before application of resin [Gray and Shellis, 2002]. Acid etching perforates and erodes the surface layer and makes the pores of the lesion body accessible for the resin. In natural caries the surface layer is locally often thicker and more mineralized than over artificial lesions. Etching natural lesions with $15 \%$ hydrochloric acid for 120 s significantly reduced the surface layer and increased resin penetration compared with etching with $37 \%$ phosphoric acid [Meyer-Lueckel et al., 2007; Paris et al., 2007b].

To further improve resin penetration into the lesion body, monomer mixtures have been optimized with regard to rapid capillary penetration [Paris et al., 2007a]. Using these improved experimental resins (so-called 'infiltrants'), significantly deeper penetration was achieved after etching with hydrochloric acid compared to an adhesive [Meyer-Lueckel and Paris, 2008a]. With the improved materials, natural caries lesions (median depth $458 \mu \mathrm{m}$ ) could be infiltrated nearly completely (penetration depth $443 \mu \mathrm{m}$ ) in vitro. Usually, because of shrinkage and incomplete penetration, not all lesion pores are infiltrated after a single application of adhesives and infiltrants. The seal can be improved by repeated application of resins [Robinson et al., 2001].

A positive side-effect of caries infiltration is that resininfiltrated lesions are optically masked. Because pores in the lesion are filled with infiltrant having a refractive index close to that of enamel, the light scattering which causes the opaque whitish appearance of caries lesions is reduced and infiltrated lesions look similar to sound enamel.

In the clinical situation, moisture and the presence of organic substances within lesion pores might hamper penetration. Nonetheless, first clinical data on primary teeth (12-month follow-up) and permanent teeth (18month follow-up) revealed a significantly reduced caries progression for infiltrated lesions $(31 \%, 11 \%)$ compared with lesions that were only subjected to fluoride applications or to oral hygiene $(61 \%, 38 \%)$ [Ekstrand et al., 2009; Paris et al., 2009].

\section{Summary and Future Perspectives}

Sealing has become more than just a procedure for permanent molars, and sealants should be regarded as an integral component of the treatment spectrum for caries ranging from non-operative approaches to restorations. It seems that the indication is shifting from solely a preventive one to now include also a therapeutic, micro- or minimally invasive technique for initial caries lesions. As control of caries activity is a prerequisite for all caries treatment, preventive sealants might lose their status as gold standard for caries prevention in pits and fissures, especially when surface-specific instructions for erupting teeth are used. In addition, resin-based sealants cannot be placed early during the critical stage of eruption and preventive sealants may fail in highly caries active individuals without sufficient reductions of the cariogenicity of the oral environment.

Thus, purely preventive sealants may become an exception and be restricted to pits and fissures in patients with a high caries risk. The indication for pit and fissure sealants should be based on individual caries risk, activity and patient compliance. In approximal surfaces, sealants or infiltrations are equivalent to composite restorations with respect to the accuracy of placement, time and costs, but they leave more tooth structure intact.

Therefore, sealing is a valuable technique for pits, fissures and possibly for approximal surfaces, which shifts the classic restorative approach towards minimal invasion, but is no alternative to true reduction of caries activity. Approximal sealing or infiltration may become a routine procedure in the near future.

In the light of these findings and discussion at the symposium, we suggest that the following components should be included in teaching curricula concerning sealants:

- Fissure sealants have been shown to be effective in controlling occlusal caries in randomized clinical trials. Concerning the sealing material, the data are inconclusive and clinical performance is influenced by many factors, especially technical equipment and caries activity.

- Fissure sealants should be seen as an integral component of the management options for caries, especially in permanent molars. For their use in the primary dentition and in premolars, less evidence exists.

- Resin-based sealants cannot be placed early during the critical stage of eruption because of difficulties of moisture control. Alternatives are non-operative caries treatment or glass ionomer sealants. 
- Indications for fissure sealants should be based on surface-specific parameters, individual caries risk, caries activity and patient compliance.

- Purely preventive sealants may become an exception and be restricted to patients with high caries risk and to whom access is difficult.

- The therapeutic indications for sealants include active lesions in pits and fissures, possibly even up to deep enamel caries or initial dentine lesions. The standard recommendation for deeper lesions is still operative procedures.
- Further evidence of safety and efficacy of sealing or infiltration of approximal lesions is required.

- Sealing in residual caries with resin-based materials or crowns slows down or arrests lesion progression through the well-known reactions of the dentine-pulp organ (reactive dentine formation).

\section{Conflict of Interest}

Hendrik Meyer-Lueckel and Sebastian Paris receive royalties from DMG.

\section{References}

Ahovuo-Saloranta A, Hiiri A, Nordblad A, Mäkelä M, Worthington HV: Pit and fissure sealants for preventing dental decay in the permanent teeth of children and adolescents. Cochrane Database Syst Rev 2008;4: CD001830.

Alkilzy M, Berndt C, Meller C, Schidlowski M, Splieth $\mathrm{CH}$ : Sealing of proximal surfaces with polyurethane tape: a two-year clinical and radiographic feasibility study. J Adhes Dent 2009;11:91-94

-Araujo AM, Naspitz GM, Chelotti A, Cai S: Effect of Cervitec on mutans streptococci in plaque and on caries formation on occlusal fissures of erupting permanent molars. Caries Res 2002;36:373-376.

-Beiruti N, Frencken JE, van't Hof MA, van Palenstein Helderman WH: Caries preventive effect of resin-based and glass ionomer sealants over time: a systematic review. Community Dent Oral Epidemiol 2006;34:403409.

Bratthall D, Hänsel-Petersson G, Sundberg H: Reasons for the caries decline: what do the experts believe? Eur J Oral Sci 1996;104:416422, discussion 423-425, 430-432.

-Carvalho JC, Ekstrand KR, Thylstrup A: Dental plaque and caries on occlusal surfaces of first permanent molars in relation to stage of eruption. J Dent Res 1989;68:773-779.

-Carvalho JC, Ekstrand KR, Thylstrup A: Results after 1 year of non-operative occlusal caries treatment of erupting permanent first molars. Community Dent Oral Epidemiol 1991;19:23-28.

Carvalho JC, Thylstrup A, Ekstrand KR: Results after 3 years of non-operative occlusal caries treatment of erupting permanent first molars. Community Dent Oral Epidemiol 1992; 20:187-192.

Davila JM, Buonocore MG, Greeley CB, Provenza DV: Adhesive penetration in human artificial and natural white spots. J Dent Res 1975;54:999-1008.
Donly KJ, Ruiz M: In vitro demineralization inhibition of enamel caries utilizing an unfilled resin. Clin Prev Dent 1992;14:22-24.

Ekstrand KR, Christiansen MEC: Outcome of a non-operative caries treatment programme for children and adolescents. Caries Res 2005;39:455-467.

Ekstrand KR, Christiansen MEC:Nexø-metoden set $\mathrm{i}$ et sundhedsfremmende perspektiv. Tandlægebladet 2008;112:112-123.

-Ekstrand KR, Martignon S, Christiansen MEC: Frequency and distribution patterns of sealants among 15-year-olds in Denmark in 2003 Community Dent Health 2007a;24:26-30.

-Ekstrand KR, Martignon S, Ricketts DJ, Qvist V: Detection and activity assessment of primary coronal caries lesions: a methodologic study. Oper Dent 2007b;32:225-235.

Ekstrand KR, Bakhshandeh A, Martignon S: Treatment of proximal superficial caries lesions on primary molar teeth with resin infiltration and fluoride varnish versus fluoride varnish only: Efficacy after 1 year. Caries Res 2010, in press.

Garçía-Godoy F, Summitt JB, Donly KJ: Caries progression of white spot lesions sealed with an unfilled resin. J Clin Pediatr Dent 1997; 21:141-143.

Goepferd SJ, Olberding P: The effect of sealing white spot lesions on lesion progression in vitro. Pediatr Dent 1989;11:14-16.

Gomez SS, Basili CP, Emilson CG: A 2-year clinical evaluation of sealed noncavitated approximal posterior carious lesions in adolescents. Clin Oral Invest 2005;9:239-243.

Gray GB, Shellis RP: Infiltration of resin into white spot caries-like lesions of enamel: an in vitro study. Eur J Prosthodont Restor Dent 2002;10:27-32.

-Griffin SO, Oong E, Kohn W, Vidakovic B, Gooch BF; CDC Dental Sealant Systematic Review Group; Bader J, Clarkson J, Fontana MR, Meyer DM, Rozier RG, Weintraub JA, Zero DT: The effectiveness of sealants in managing caries lesions. J Dent Res 2008;87: 169-174.
Heyduck C, Meller C, Schwahn C, Splieth CH: Effectiveness of sealants in adolescents with high and low caries experience. Caries Res 2006;40:375-381

Hiiri A, Ahovuo-Saloranta A, Nordblad A, Mäkelä M: Pit and fissure sealants versus fluoride varnishes for preventing dental decay in children and adolescents. Cochrane Database Syst Rev 2006;4:CD003067.

-Innes NP, Evans DJ, Stirrups DR: The Hall Technique: a randomized controlled clinical trial of a novel method of managing carious primary molars in general dental practice: acceptability of the technique and outcomes at 23 months. BMC Oral Health 2007;7:18.

Ismail AI, Sohn W, Tellez M, Amaya A, Sen A, Hasson H, Pitts NB: The International Caries Detection and Assessment System (ICDAS): an integrated system for measuring dental caries. Community Dent Oral Epidemiol 2007;35:170-178.

Jensen OE, Handelman SL: Effect of an autopolymerising sealant on viability of microflora in occlusal dental caries. Scand J Dent Res 1980;88:382-388

Kidd EA, Fejerskov O: What constitutes dental caries? Histopathology of carious enamel and dentin related to the action of cariogenic biofilms. J Dent Res 2004;83(special issue C):C35-C38.

Marinho VC, Higgins JP, Logan S, Sheiham A: Fluoride gels for preventing dental caries in children and adolescents. Cochrane Database Syst Rev 2002;2:CD002280.

Marinho VC, Higgins JP, Sheiham A, Logan S: Fluoride toothpastes for preventing dental caries in children and adolescents. Cochrane Database Syst Rev 2003;1:CD002278.

Marthaler TM, O’Mullane DM, Vrbic V: The prevalence of dental caries in Europe 19901995. ORCA Saturday Afternoon Symposium 1995. Caries Res 1996;30:237-255. 
Martignon S, Chavarria N, Ekstrand KR: Caries status and proximal lesion behaviour during a 6-year period in young adult Danes: an epidemiological investigation. Clin Oral Investig DOI: 10.1007/s00784-009-0306-0.

-Martignon S, Ekstrand K, Ellwood R: Efficacy of sealing proximal early active lesions: an 18month clinical study evaluated by conventional and subtraction radiography. Caries Res 2006;40:382-388.

McDonald SP, Sheiham A: The distribution of caries on different tooth surfaces at varying levels of caries - a compilation of data from 18 previous studies. Community Dent Health 1992;9:39-48.

-Mejàre I, Källestål C, Stenlund H: Incidence and progression of approximal caries from 11 to 22 years of age in Sweden: a prospective radiographic study. Caries Res 1999;33:93100.

Mejàre I, Källestål C, Stenlund H, Johansson H: Caries development from 11 to 22 years of age: a prospective radiographic study. Prevalence and distribution. Caries Res 1998;32: 10-16.

Mejàre I, Lingström P, Petersson LG, Holm AK, Twetman S, Källestål C, Nordenram G, Lagerlöf F, Söder B, Norlund A, Axelsson S, Dahlgren H: Caries-preventive effect of fissure sealants: a systematic review. Acta Odontol Scand 2003;61:321-330.

-Mejàre I, Stenlund H, Zelezny-Holmlund C: Caries incidence and lesion progression from adolescence to young adulthood: a prospective 15-year cohort study in Sweden. Caries Res 2004;38:130-141.

-Mertz-Fairhurst EJ, Curtis JW Jr, Ergle JW, Rueggeberg FA, Adair SM: Ultraconservative and cariostatic sealed restorations: results at year 10. J Am Dent Assoc 1998;129: 55-66.

Meyer-Lueckel H, Mueller J, Paris S, Hummel M, Kielbassa AM: Penetration verschiedener Adhäsive in initialen Schmelzläsionen in vitro. Schweiz Monatsschr Zahnmed 2005; 115:316-323.
Meyer-Lueckel H, Paris S: Improved resin infiltration of caries lesions. J Dent Res 2008a;87: 1112-1116.

Meyer-Lueckel H, Paris S: Progression of artificial enamel caries lesions after infiltration with experimental light curing resins. Caries Res 2008b;42:122-128.

Meyer-Lueckel H, Paris S, Kielbassa AM: Surface layer erosion of natural caries lesions with phosphoric and hydrochloric acid gels. Caries Res 2007;41:223-230.

-Mueller J, Meyer-Lueckel H, Paris S, Hopfenmuller W, Kielbassa AM: Inhibition of lesion progression by penetration of resins in vitro: influence of the application procedure. Oper Dent 2006;31:339-346.

Oong EM, Griffin SO, Kohn WG, Gooch BF, Caufield PW: The effect of dental sealants on bacteria levels in caries lesions: a review of the evidence. J Am Dent Assoc 2008;139: 271-278.

Paris S, Hopfenmuller W, Meyer-Lueckel H: Res in infiltration of caries lesions: an efficacy randomized trial. J Dent Res 2009 (submitted).

Paris S, Meyer-Lueckel H, Colfen H, Kielbassa AM: Resin infiltration of artificial enamel caries lesions with experimental light curing resins. Dent Mater J 2007a;26:582-588.

-Paris S, Meyer-Lueckel H, Kielbassa AM: Resin infiltration of natural caries lesions. J Dent Res 2007b;86:662-666.

Paris S, Meyer-Lueckel H, Mueller J, Hummel M, Kielbassa AM: Progression of sealed initial bovine enamel lesions under demineralizing conditions in vitro. Caries Res 2006;40:124129.

Ricketts DN, Ekstrand KR, Martignon S, Ellwood R, Alatsaris M, Nugent Z: Accuracy and reproducibility of conventional radiographic assessment and subtraction radiography in detecting demineralization in occlusal surfaces. Caries Res 2007;41:121-128.

Ricketts DN, Kidd EA, Innes N, Clarkson J: Complete or ultraconservative removal of decayed tissue in unfilled teeth. Cochrane Database Syst Rev 2006;3:CD003808.
Robinson C, Brookes SJ, Kirkham J, Wood SR, Shore RC: In vitro studies of the penetration of adhesive resins into artificial caries-like lesions. Caries Res 2001;35:136-141.

Robinson C, Hallsworth AS, Weatherell JA, Kunzel W: Arrest and control of carious lesions: a study based on preliminary experiments with resorcinol-formaldehyde resin. J Dent Res 1976;55:812-818.

Rodda JC: Impregnation of caries-like lesions with dental resins. N Z Dent J 1983;79:114117.

Salar DV, García-Godoy F, Flaitz CM, Hicks MJ: Potential inhibition of demineralization in vitro by fluoride-releasing sealants. J Am Dent Assoc 2007;138:502-506

$>$ Schmidlin PR, Göhring TN, Roos M, Zehnder $\mathrm{M}$ : Wear resistance and surface roughness of a newly devised adhesive patch for sealing smooth enamel surfaces. Oper Dent 2006a;31:115-121.

Schmidlin PR, Klück I, Zimmermann J, Roulet JF, Seemann R: Caries-preventive potential of an adhesive patch after thermomechanical loading: a microbial-based in vitro study. J Adhes Dent 2006b;8:7-12.

Schmidlin PR, Zehnder M, Pasqualetti T, Imfeld T, Besek MJ: Penetration of a bonding agent into de- and remineralized enamel in vitro. J Adhes Dent 2004;6:111-115.

Schmidlin PR, Zehnder M, Zimmermann MA, Zimmermann J, Roos M, Roulet JF: Sealing smooth enamel surfaces with a newly devised adhesive patch: a radiochemical in vitro analysis. Dent Mater 2005;21:545-550.

Schwartz M, Gröndahl H-G, Pliskin S, Boffa J: A longitudinal analysis from bite-wing radiographs of the rate of progression of approximal carious lesions through human dental enamel. Arch Oral Biol 1984;29:529-536.

Tagami J, Hosoda H, Fusayama T: Optimal techniques of etching enamel. Oper Dent 1988; 13:181-184.

Tanaka M, Matsunaga K, Kadoma Y: Use of fluoride-containing sealant on proximal surfaces. J Med Dent Sci 2000;47:49-53.

WHO: Caries for 12-year-olds by country/area. WHO, 2003. http://www.whocollab.odont. lu.se/countriesalphab.html. 